\title{
ResearchArticle
}

\section{Biochemical evidence for anti-autistic potential of Asparagus racemosus}

\author{
Priya Joon, Dinesh Dhingra and Milind Parle
}

\section{SUMMARY}

Autism is a serious developmental disorder observed in early childhood that impairs the ability to communicate and interact socially. It is also characterized by a tendency to engage in repetitive behaviours, apathy and cognitive decline. Asparagus racemosus commonly known as Shatavari has been found to possess neuro-protective, nootropic, antidepressant and anti-anxiety activities. In the light of above, a project was designed to study involvement of acetylcholine, catecholamines and oxidative stress in manifestation of autistic symptoms induced by valproic-acid in rat pups and their modulation by Asparagus racemosus (Shatavari). A single intraperitoneal injection of sodium valproate $(500 \mathrm{mg} / \mathrm{kg}) \mathrm{was}$ given on $13^{\text {th }}$ day of gestation to pregnant Wistar female rats for inducing autism in rat pups. Asparagus racemosus root extract (100 and $200 \mathrm{mg} / \mathrm{kg}$, p.o.) significantly reduced valproic acid- induced oxidative stress as indicated by decrease in plasma nitrite levels, increase in brain GSH levels and enhancement of catalase activity in brains of autistic rat pups. Furthermore, Asparagus racemosus (Shatavari) diminished acetylcholinesterase and monoamine oxidase-A enzyme activity in autistic pups. Shatavari restored valproic acid-induced biochemical deficits of rat pups in the present study. The present research findings, justify the status of Shatavari as a powerful medicinal herb for improving women's health. Autism spectrum disorder which has its origin in abnormal fetal development probably can be best treated by the use of this herb.

Key Words : Autism, Shatavari, Oxidative stress, AchE, MAO-A, Women-health

How to cite this article : Joon, Priya, Dhingra, Dinesh and Parle, Milind (2020). Biochemical evidence for anti-autistic potential of Asparagus racemosus. Internat. J. Plant Sci., 15 (1): 42-51, DOI: 10.15740/HAS/IJPS/15.1/42-51, Copyright@ 2020: Hind AgriHorticultural Society.

Article chronicle : Received : 14.11.2019; Revised : 09.12.2019; Accepted : 24.12.2019

\section{MEMBERS OF THE RESEARCH FORUM}

Author to be contacted :

Milind Parle, Delhi Pharmaceutical Sciences and Research University, Campus (DIPSAR), PushpVihar, New Delhi, India

Email : mparle@ rediffmail.com

Address of the Co-authors:

Priya Joon and Dinesh Dhingra, Pharmacology Division, Department of Pharmaceutical Sciences, Guru Jambheshwar University of Science and Technology, (A-Grade State Technical University), Hisar (Haryana) India

Email : piks.priya@gmail.com 